\title{
CARBIDE PRECIPITATION IN NICKEL BASE SUPERALLOYS 718 AND 625 AND THEIR EFFECT ON MECHANICAL PROPERTIES
}

\author{
M. Sundararaman, P. Mukhopadhyay and S. Banerjee \\ Materials Science Division \\ Bhabha Atomic Research Centre \\ Mumbai 400 085, India.
}

\begin{abstract}
$\underline{\text { Abstract }}$
In addition to the precipitation of the strengthening intermetallic phases, namely, the metastable $\gamma$ " and $\gamma$ ' phases, carbide phases also precipitate during age hardening heat treatments of Alloy 718 and Alloy 625. A detailed investigation has been carried out on the precipitation of primary and secondary carbide phases in these two alloys with reference to their identity, distribution and morphology. It has been found that the predominant carbide phase in Alloy 718 is a niobium rich MC phase, while in the case of Alloy 625 , mainly $\mathrm{M}_{23} \mathrm{C}_{6}$ and, to some extent, $\mathrm{M}_{6} \mathrm{C}$ type carbides precipitate. Carbide precipitation during ageing has been seen to be confined almost exclusively to the austenite grain boundaries in both the alloys. $\mathrm{NbC}$ formation at the grain boundaries in Alloy 718 is associated with the appearance of distinct intermetallic precipitate ( $\gamma^{\prime \prime}$ and $\gamma^{\prime}$ ) free zones near these boundaries whereas in Alloy 625, no well defined intermetallic precipitate free zones (PFZ) have been observed. The precipitation of different types of grain boundary carbides is discussed in terms of the differences in the chemistry of these alloys. The presence or absence of PFZ at grain boundaries is discussed in the light of solute depletion/vacancy depletion mechanisms.

The influence of grain boundary carbide precipitation on the mechanical behaviour, especially the fracture mode, of these alloys has also been examined. It has been found that the progressive coverage of these boundaries with carbide particles results in a gradual transition in the fracture mode from transgranular to intergranular. Microcracks have often been found to nucleate at the matrix-carbide interface at the points of impingement of deformation bands.
\end{abstract}

Superalloys 718, 625, 706 and Various Derivatives

Edited by E.A. Loria

The Minerals, Metals \& Materials Society, 1997 


\section{Introduction}

Alloy 718 and Alloy 625 are strengthened by precipitates of the metastable $\gamma$ " phase (body centred tetragonal $\mathrm{DO}_{22}$ structure, having $\mathrm{Ni}_{3} \mathrm{Nb}$ composition), uniformly distributed in the matrix [1,2]. In addition to $\gamma^{\prime \prime}$ a small volume fraction of the $\gamma^{\prime}$ phase (primitive cubic $\mathrm{L1}_{2}$ structure) also precipitates on ageing in Alloy 718 [3]. The equilibrium intermetallic precipitate phase in both the alloys is the $\delta-\mathrm{Ni}_{3} \mathrm{Nb}$ phase (orthorhombic $\mathrm{DO}_{\mathrm{a}}$ structure) [4]. These alloys have good corrosion resistance in a variety of aggressive environments and are resistant to oxidation up to about $1000^{\circ} \mathrm{C}$. The sluggish response of these alloys to age hardening enables them to be welded and annealed with no spontaneous hardening. Because of this attractive combination of properties Alloy 718 and Alloy 625 have found widespread applications.

During ageing treatments, carbide precipitation has been found to occur at austenite grain boundaries in both the alloys in addition to intermetallic phase precipitation in the matrix $[5,6]$. It has been reported that a continuous $\mathrm{MC}$ carbide film at grain boundaries, flanked by precipitate free zones, reduces the notch ductility of Alloy 718 [7]. $\mathrm{M}_{6} \mathrm{C}$ and $\mathrm{M}_{23} \mathrm{C}_{6}$ carbides have been observed to precipitate at grain boundaries in Alloy 625 on ageing [8]. Notch ductility and impact energy have been found to be reduced due to the precipitation of these carbides in Alloy 625 [9].

The present paper deals with the precipitation of carbide phases in these two alloys with special reference to their nucleation sites, morphology, distribution, identity and temperature regimes of occurrence. The formation of intermetallic precipitate free zones in the vicinity of the carbide precipitates has also been examined and the influence of these grain boundary precipitates on the fracture behaviour has been discussed.

\section{Experimental Procedure}

The chemical compositions of the two alloys used in this work are shown in Table 1. As received sheets of both the alloys were cold rolled to yield thinner strips of 0.3 to $0.5 \mathrm{~mm}$ thickness. Samples of suitable dimensions, encapsulated in silica capsules under a helium atmosphere, were solution treated at temperatures in the range of $1200^{\circ} \mathrm{C}$ to $1000^{\circ} \mathrm{C}$. Solution treated and quenched samples were subsequently aged at temperatures in the range of $600^{\circ} \mathrm{C}$ $900^{\circ} \mathrm{C}$ for various periods of time to precipitate the intermetallic and the secondary carbide phases. Heat treated tensile specimens were deformed to failure at room temperature in air in a floor model Instron machine, using a strain rate of $6.67 \times 10^{-4} \mathrm{~s}^{-1}$. Fractographic examination of the fracture surfaces was conducted by scanning electron microscopy (SEM). Microstructural examination was carried out mainly by transmission electron microscopy (TEM). Sample preparation for TEM has been described elsewhere [10].

\section{Results}

\section{Carbide precipitation in the solution treated alloys}

Coarse carbide particles, often irregular in shape, were found to be distributed in a non uniform manner within the austenite grains as well as at the grain boundaries and incoherent segments of twin boundaries (Fig.1a and 1b). SAD patterns matched with reciprocal lattice sections corresponding to $\mathrm{MC}$ carbides. The lattice parameter was found to lie between the reported lattice parameters of $\mathrm{NbC}$ and $\mathrm{TiC}$ phases, being closer to the former. In view of this observation it was concluded that some titanium was also incorporated in the MC carbide phase; this was in conformity with the results of EDS analysis (Fig. 1c). When Alloy 625 was solutionised in the temperature range of $1050^{\circ} \mathrm{C}$ to $1000^{\circ} \mathrm{C}$, blocky particles of another phase were encountered; this phase was identified using electron diffraction to be of $\mathrm{M}_{6} \mathrm{C}$ type (Fig.1d). 
Table 1. Chemical Composition of Alloy 718 and Alloy 625 in wt.\%

\begin{tabular}{|c|ccccccccccc|}
\hline Alloy & $\mathrm{Ni}$ & $\mathrm{Cr}$ & $\mathrm{Mo}$ & $\mathrm{Nb}$ & $\mathrm{Fe}$ & $\mathrm{Al}$ & $\mathrm{Ti}$ & $\mathrm{Mn}$ & $\mathrm{Si}$ & $\mathrm{C}$ & $\mathrm{Co}$ \\
\hline 718 & 52.67 & 18.37 & 2.91 & 6.00 & 18.06 & 1.00 & 0.45 & 0.21 & 0.29 & 0.04 & - \\
\hline 625 & 61.9 & 21.0 & 9.05 & 3.70 & 3.50 & 0.17 & 0.23 & 0.14 & 0.15 & 0.05 & 0.08 \\
\hline
\end{tabular}

These carbide particles were not observed in samples solution treated at temperatures above $1100^{\circ} \mathrm{C}$. SAD patterns obtained from carbide particles in solution treated samples showed that they did not bear any orientation relationship with the matrix [11]. The primary carbide particle size appeared to vary over a wide range.

\section{Carbide precipitation during ageing}

The primary carbide particles were observed in the aged samples also. Their shape, size and distribution did not undergo any conspicuous change during ageing treatments. No fresh carbide precipitation appeared to occur within the grains due to the ageing treatments. Grain boundaries and incoherent segments of twin boundaries, however, appeared to be the preferred nucleation sites for secondary carbide precipitation. These grain boundary carbide precipitates were very small in the initial stages of ageing and were identified on the basis of SAD patterns. The nature of the carbide particles precipitating at the grain boundaries in the two alloys was quite different. The kinetics of carbide precipitation appeared to be more rapid in Alloy 625 than in Alloy 718, particularly at lower ageing temperatures.

\section{Alloy 718}

No grain boundary carbide precipitates were encountered on ageing at $650^{\circ} \mathrm{C}$ for up to $168 \mathrm{~h} ; \gamma^{\prime}$ and $\gamma^{\prime \prime}$ precipitates, distributed uniformly throughout the grains right up to the grain boundaries, could be observed [11]. In samples aged at $700^{\circ} \mathrm{C}$ for periods extending to $90 \mathrm{~h}$, no grain boundary carbide precipitation was seen to have occurred. On increasing the ageing time to $168 \mathrm{~h}$, profuse carbide precipitation was noticed at some grain boundaries while many others were devoid of carbide precipitates. The fraction of grain boundaries at which carbide precipitation occurred increased with increasing ageing time. At $336 \mathrm{~h}$, almost all grain boundaries were decorated with carbide particles (Fig. 2a). SAD patterns obtained from these precipitates could be matched with those arising from the $\mathrm{NbC}$ phase. In addition to $\mathrm{NbC}$, some chunky $\mathrm{M}_{23} \mathrm{C}_{6}$ particles were also observed. Grain boundary precipitation was significantly enhanced when the ageing temperature was raised to $750^{\circ} \mathrm{C}$. Ageing at this temperature for short periods caused the precipitation of discrete carbide particles at some grain boundaries. When ageing was carried out at this temperature for $100 \mathrm{~h}$, nearly all the grain boundaries were decorated with almost contiguous carbide particles which gave the appearance of a continuous film of the carbide phase (Fig. 2b). Such carbide decorated grain boundaries were flanked on both sides by well defined intermetallic precipitate free zones. This feature has been described in greater detail in a later section.

On raising the ageing temperature to $800^{\circ} \mathrm{C}$, co-precipitation of $\mathrm{NbC}$ and the equilibrium $\delta$ phase was observed to occur at the grain boundaries (Fig. 2c). These two phases appeared to compete for grain boundary nucleation sites. On increasing the ageing temperature to $900^{\circ} \mathrm{C}$, only $\delta$ precipitation was observed at the grain boundaries. A cube to cube orientation relationship with the austenite matrix was exhibited by both $\mathrm{NbC}$ and $\mathrm{M}_{23} \mathrm{C}_{6}$ carbides. A TTP diagram constructed with regard to grain boundary precipitation on ageing in Alloy 718 is shown in Fig.2d. The nose of the TTP curve corresponding to the shortest incubation time was found 

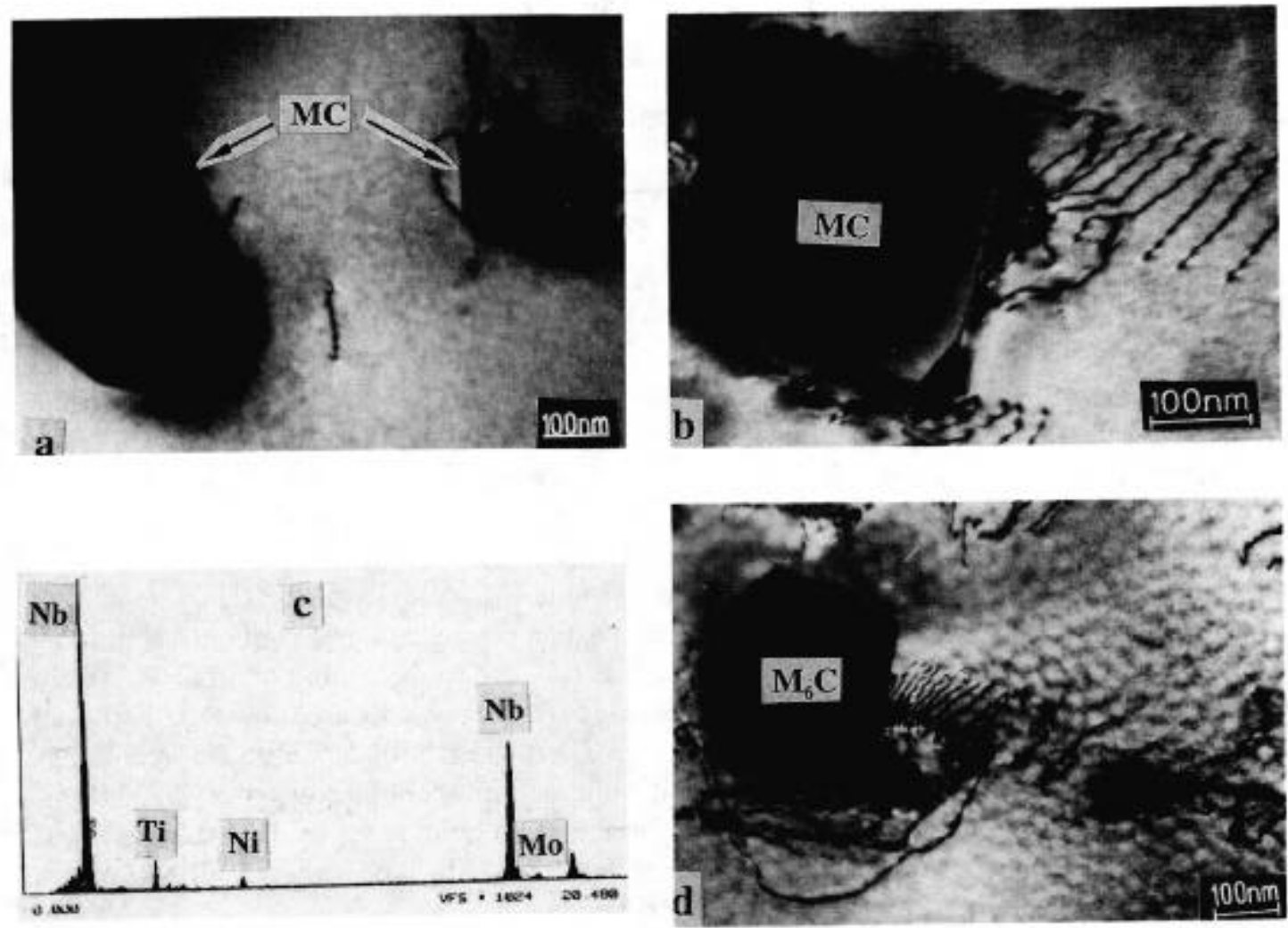

Fig.1. Primary MC type carbide in (a) Alloy 718 and (b) in Alloy 625 solutionised at $1100^{\circ} \mathrm{C}$ for $1 \mathrm{~h}$. (c) EDS spectrum of primary carbide particle revealing incorporation of titanium in MC carbide (d) $\mathrm{M}_{6} \mathrm{C}$ type carbide in Alloy 625 solutionised at $1000^{\circ} \mathrm{C}$ for $1 \mathrm{~h}$.

to occur around $750^{\circ} \mathrm{C}$ for $\mathrm{NbC}$ precipitation.

\section{Alloy 625}

Carbide precipitation during ageing was observed in this alloy right from $650^{\circ} \mathrm{C}$ onwards. A nearly continuous layer was found to have formed at many grain boundaries (Fig.3a) at this ageing temperature. The precipitation kinetics was considerably enhanced when the ageing temperature was raised to $700^{\circ} \mathrm{C}$. The average carbide particle size and the thickness of the grain boundary carbide layer increased with increasing ageing time. As in the case of Alloy 718, the extent of precipitation was found to vary from grain boundary to grain boundary. Some of these boundaries were seen to be associated with $\gamma^{\prime \prime}$ precipitate free zones in the grains adjacent to them (described in the next section). The morphology and the distribution of the grain boundary carbide particles remained essentially unaltered when the ageing temperature was raised to $750^{\circ} \mathrm{C}$ (Fig. 3b). Some of these precipitates grew quite large and advanced into the grains flanking the boundary. Carbide particles located at grain boundary trijunctions were generally coarser than other particles. Since $\gamma^{\prime \prime}$ precipitation was almost entirely confined to dislocations and coherent twin boundaries at this temperature, no $\gamma^{\prime \prime}$ free zones were observed in the vicinity of the grain boundaries. Apart from grain boundaries, heterogeneous nucleation of the carbide phase occurred quite extensively on incoherent segments of annealing twin boundaries (Fig.3c). When the ageing temperature was raised to $800^{\circ} \mathrm{C}$ and beyond, co-precipitation of the carbide 
and the $\delta$ phases occurred quite frequently at the grain boundaries with a large average interparticle spacing between them (Fig.3d). $\mathrm{NbC}$ precipitation was seldom observed at the grain boundaries in this alloy during the ageing treatments employed in this study. SAD patterns obtained from the grain boundary carbide particles could be indexed in terms of the $\mathrm{M}_{23} \mathrm{C}_{6}$ and the $\mathrm{M}_{6} \mathrm{C}$ type phases. These carbide precipitates were found to have a cube to cube orientation relationship with the austenite matrix. Earlier investigations on this alloy have revealed that $\mathrm{NbC}$ and $\mathrm{M}_{23} \mathrm{C}_{6}$ type carbides form at grain boundaries when the ageing temperature is below $850^{\circ} \mathrm{C}$ while $\mathrm{M}_{6} \mathrm{C}$ type particles precipitate at higher temperatures [8].

\section{Intermetallic precipitate free zones}

Extensive carbide precipitation on grain boundaries was accompanied by a concomitant formation of intermetallic precipitate free zones in the matrix regions adjacent to them in Alloy 718. The widths of these zones and the clarity with which they were delineated appeared to vary from boundary to boundary. Earlier investigations [11] on the measurement of PFZ widths in this alloy had indicated that the PFZ width increased with increasing ageing time and also with increase in the width of the near continuous grain boundary precipitate layer. In Alloy 718, two distinct intermetallic precipitate free zones, one showing the absence of $\gamma$ ' particles and the other showing the absence of $\gamma^{\prime \prime}$ particles, were observed (Fig.4a). The former was generally narrower than the latter. This indicated that the enhanced solubility of the intermetallic phases in the
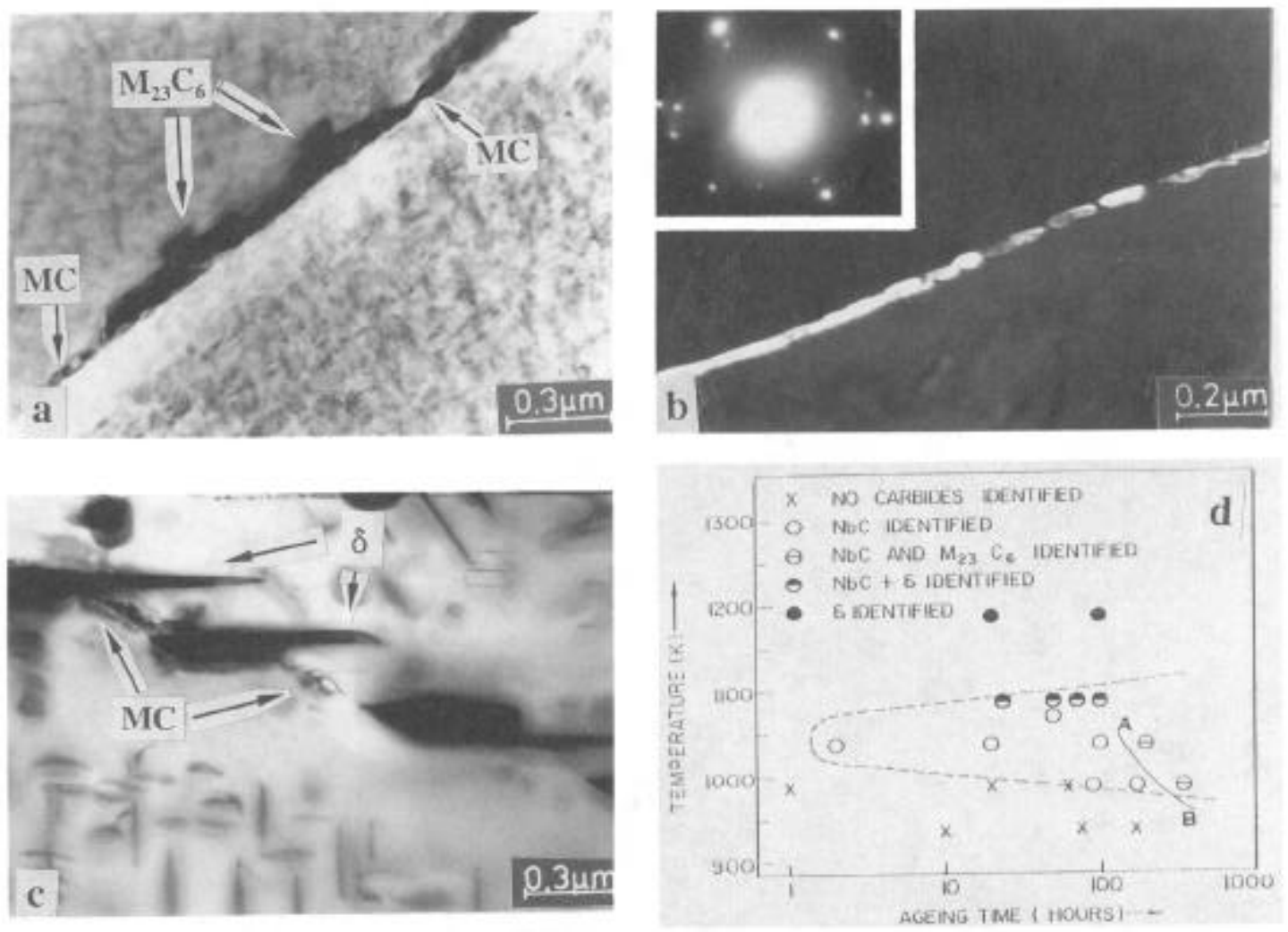

Fig.2. NbC carbide precipitation at grain boundaries in Alloy 718 aged at (a) $700^{\circ} \mathrm{C}$ for $336 \mathrm{~h}$; (b) $750^{\circ} \mathrm{C}$ for $100 \mathrm{~h}$; and (c) $800^{\circ} \mathrm{C}$ for $48 \mathrm{~h} ; \mathrm{M}_{23} \mathrm{C}_{6}$ and $\delta$ phases forming at a grain boundary are indicated by arrows. Inset shows an $<110>$ zone axis $\mathrm{SAD}$ pattern corresponding to $\mathrm{NbC}$ obeying a cube to cube relationship with the austenite. (d) TTP diagram corresponding to NbC precipitation. 

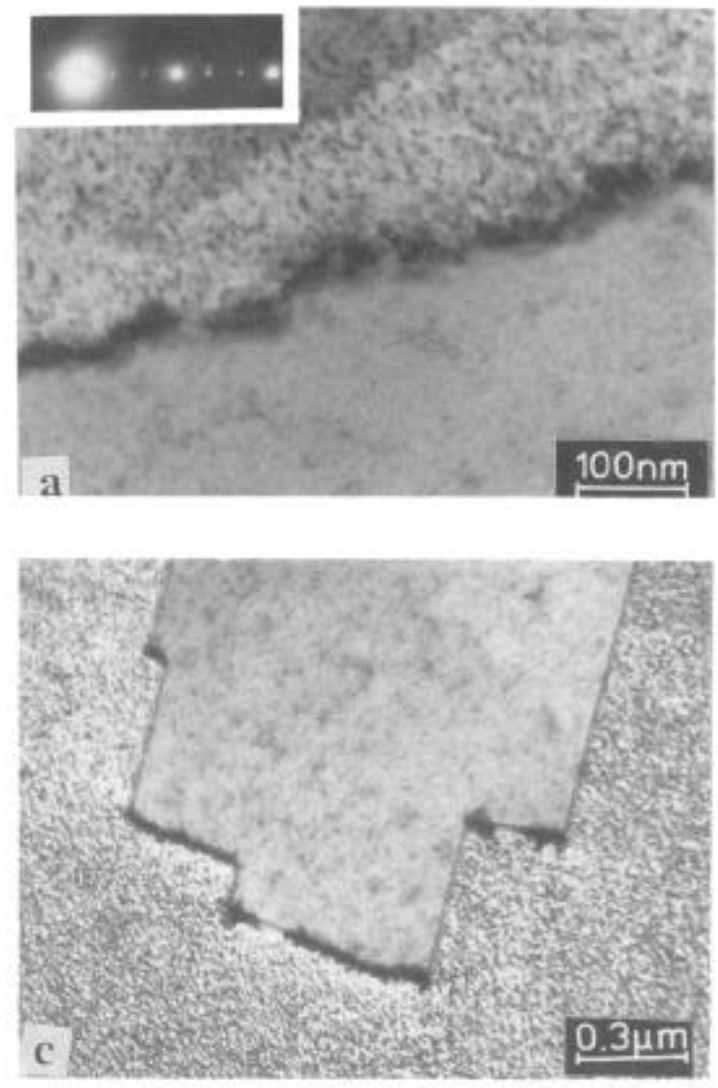
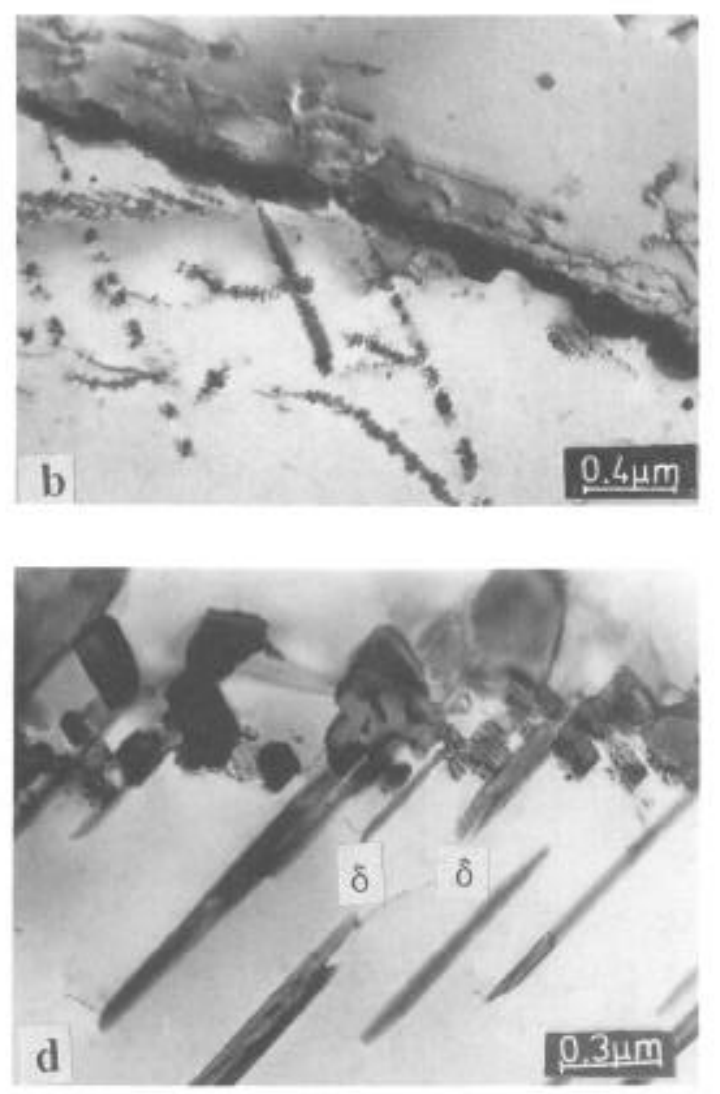

Fig.3. $\mathrm{M}_{23} \mathrm{C}_{6}$ carbide precipitation at grain boundaries in Alloy 625 aged at (a) $650^{\circ} \mathrm{C}$ for 90 h; (b) $750^{\circ} \mathrm{C}$ for $24 \mathrm{~h}$; (c) $\mathrm{M}_{23} \mathrm{C}_{6}$ carbide precipitation at incoherent segments of twin boundaries. (d) co- precipitation of carbide and $\delta$ at a grain boundary (ageing: $800^{\circ} \mathrm{C}$ for $240 \mathrm{~h}$ ).
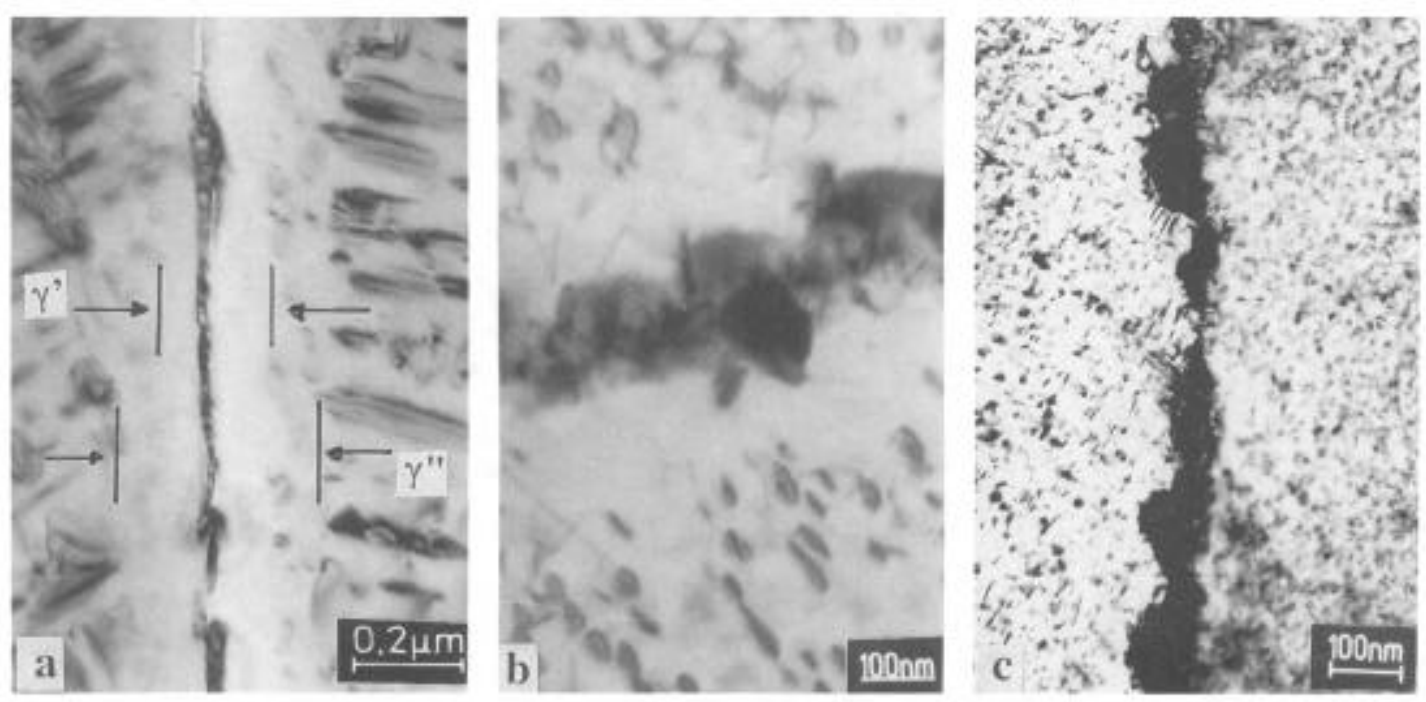

Fig.4. (a) $\gamma^{\prime}$ and $\gamma^{\prime \prime}$ precipitate free zones around almost contiguous $\mathrm{NbC}$ precipitates at grain boundaries in Alloy 718 aged at $750^{\circ} \mathrm{C}$ for $100 \mathrm{~h}$. (b) and (c) $\mathrm{M}_{23} \mathrm{C}_{6}$ carbide precipitation at grain boundaries in Alloy 625 aged at $700^{\circ} \mathrm{C}$ for $200 \mathrm{~h}$. $\gamma^{\prime \prime}$ precipitate free zones could be observed around grain boundaries in (b). 
austenite, brought about locally by grain boundary carbide precipitation, extended to a larger distance in the case of the $\gamma^{\prime \prime}$ phase than in the case of the $\gamma^{\prime}$ phase. In the case of Alloy 625,

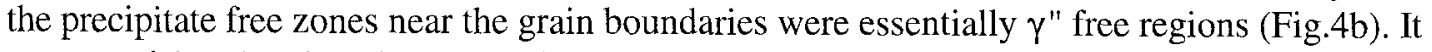
was surprising that though near continuous carbide films formed on many grain boundaries, only a few of them had clear $\gamma^{\prime \prime}$ precipitate free zones surrounding them (Fig. $4 \mathrm{c}$ ).

\section{Effect of grain boundary carbide precipitation on fracture mode}

In both these alloys, the formation of carbide precipitates at the grain boundaries appeared to have a significant influence on the alloy fracture mode. In the solution treated condition as well as after brief or low temperature ageing treatments (which were insufficient to bring about any significant amount of grain boundary carbide precipitation) both the alloys fractured in a transgranular manner by microvoid coalescence. An increase in grain boundary carbide precipitation as a result of an increase in the ageing time and/or the ageing temperature caused the overall fracture mode to be a mixture of the transgranular and the intergranular modes (Fig.5). When all the grain boundaries were covered with near continuous carbide layers, the alloy fracture mode became predominantly intergranular. The transition in the fracture mode from transgranular to intergranular is illustrated in Fig.5 and Fig.6 for Alloy 718 and Alloy 625 respectively. When ageing was carried out at temperatures high enough to cause co-precipitation of $\delta$ and well separated discrete carbide particles at the grain boundaries, transgranular dimple fracture was observed. All these evidences suggested that a prerequisite for the occurrence of intergranular fracture was the presence of a near continuous carbide layer at the grain boundaries.

TEM examination of heavily deformed samples revealed that microcracks often occurred around the points of impingement of deformation bands on grain boundary carbide particles (Fig.7). These cracks might have acted as nucleation sites for intergranular fracture initiation. The occurrence of such microcracks in the vicinity of grain boundaries could not be observed in samples which were heavily deformed but did not contain significant carbide precipitate populations at the boundaries.

\section{Discussion}

\section{Primary carbides}

The observation that niobium rich MC type primary carbide particles occurred in these niobium bearing alloys was consistent with the findings of earlier investigations $[1,2,6]$. The formation of primary $\mathrm{M}_{6} \mathrm{C}$ carbide particles during the solidification of molybdenum rich nickel base alloys is known to occur [6]. In view of the high molybdenum content of Alloy 625, the observed occurrence of primary $\mathrm{M}_{6} \mathrm{C}$ precipitates in this alloy was not unexpected. Microstructural features such as irregular and blocky morphologies, nonuniform distribution at intragranular as well as intergranular locations, and the absence of any definite crystallographic orientation relationship with the surrounding austenite matrix were indicative of the fact that these carbides could have formed during solidification of the alloy.

\section{Carbide precipitation during ageing}

The solubility of carbon in the austenite is reduced by the presence of strong carbide forming elements [12 ]. The presence of such clements in significant amounts in Nlloy 718 and Alloy 625 is indicative of very restricted carbon solubilities in the $\gamma$ phase. On ageing the alloys at temperatures at which the atoms of the carbide forming species were sufficiently mobile, the carbon supersaturation of the solution treated and quenched austenite would be relieved by the 

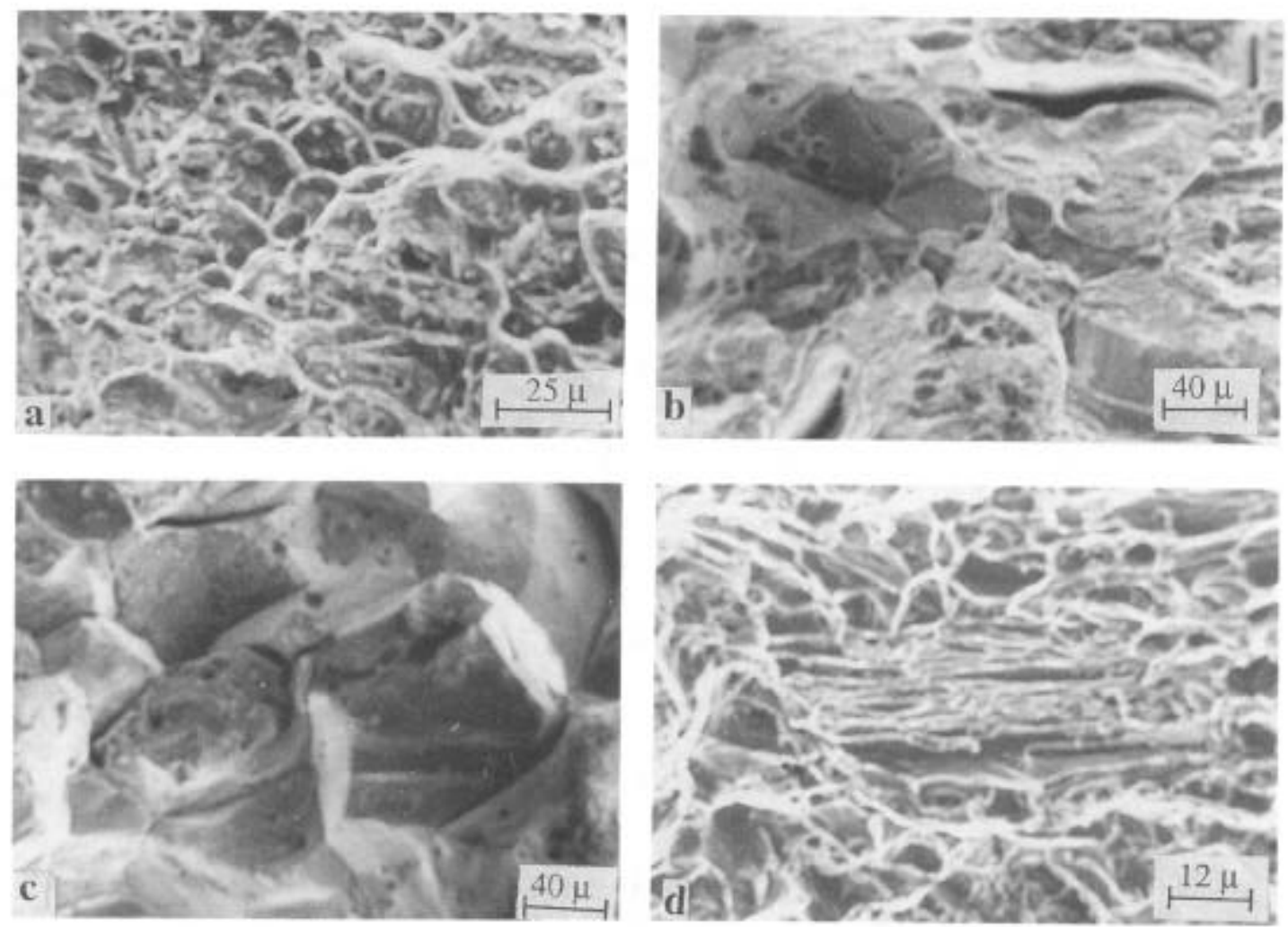

Fig.5. Fracture mode in Alloy 718 aged at (a) $650^{\circ} \mathrm{C}$ for $24 \mathrm{~h}$; (b) $700^{\circ} \mathrm{C}$ for $168 \mathrm{~h}$; (c) $750^{\circ} \mathrm{C}$ for $100 \mathrm{~h}$; and (d) $900^{\circ} \mathrm{C}$ for $114 \mathrm{~h}$. Fracture mode is transgranular in (a) and (d), partly transgranular in (b) and completely intergranular in (c). This change in fracture mode correlates well with $\mathrm{NbC}$ carbide precipitation at grain boundaries.

formation of carbide precipitates. Merrick [13] has pointed out that in nickel base alloys carbide precipitation occurs mainly at grain boundaries and dislocations. The observations made on these two alloys clearly indicated that grain boundaries were the preferred nucleation sites for carbide precipitation. This was in keeping with the general observation that carbides prefer grain boundaries as nucleation sites in nickel base alloys unlike in cobalt base and iron base alloys characterised by higher electron vacancy numbers, where intragranular precipitation sites can be quite common [14]. The maximum reduction in the free energy activation barrier for nucleation can be obtained for grain boundary precipitation [15]. Some other factors that promote preferred nucleation at grain boundaries are : (i) certain types of solute atoms segregate to grain boundaries, facilitating the formation of the critical nuclei and (ii) diffusion is faster along grain boundaries. The observation that the extent of grain boundary carbide precipitation varied from boundary to boundary is a common feature of heterogeneous precipitation at grain boundaries [16]. This variation could be attributed to variations in the boundary energy, the contact angle between the precipitate and the boundary [15] and the extent of misorientation of the boundary from the coincidence site relation [16]. For example, in a high angle boundary like a coherent twin boundary corresponding to the coincidence site relation $\Sigma=3$, no carbide precipitation was observed in these alloys. Pumphrey [17] and Butler and Swann [18] have concluded that the relationship between the precipitate habit plane and the grain boundary plane plays a significant role in grain boundary precipitation. 


\section{Nature of carbide precipitates}

The predominant grain boundary precipitate phase in Alloy 718 could be unambiguously identified as a niobium rich MC phase. High niobium contents are known to favour the formation of the MC phase in nickel base alloys [8]. The significant niobium content of Alloy 718 appeared to be responsible for promoting the precipitation of a niobium rich $\mathrm{MC}$ carbide. The predominant grain boundary carbides in Alloy 625 could be of either $M_{23} C_{6}$ or $M_{6} C$ type since the SAD patterns could be matched with reciprocal lattice sections corresponding to both these phases. However, EDS analysis could be used to differentiate between $M_{6} C$ and $M_{23} C_{6}$ type carbides. Raghavan et al. [19] have observed that in $\mathrm{M}_{6} \mathrm{C}$, chromium can substitute for molybdenum up to $30 \%$ while in $\mathrm{M}_{23} \mathrm{C}_{6}$ the solubility of molybdenum is only $10 \%$ in Ni-Cr-Mo alloys. Moreover, when the ratio of the concentration of chromium to that of molybdenum in the alloy exceeds $3, \mathrm{M}_{23} \mathrm{C}_{6}$ nucleates predominantly; when this ratio is less than $3_{6} \mathrm{M} C$ type carbides precipitate [19]. In the Alloy 625 used in this study, the chromium to molybdenum ratio was about 3. It has been reported earlier that at ageing temperatures above $850^{\circ} \mathrm{C}, \mathrm{M}_{6} \mathrm{C}$ type carbides form predominantly while at temperatures below $850^{\circ} \mathrm{C}, \mathrm{M}_{23} \mathrm{C}_{6}$ type carbides precipitate $[6,8]$. A limited amount of EDS analysis was carried out on this alloy in the present work and the results conformed to this observation. It was quite possible that along with $\mathrm{M}_{23} \mathrm{C}_{6}$ precipitation, $\mathrm{M}_{6} \mathrm{C}$ precipitation also occurred to some extent. Both these phases exhibited a cube to cube orientation relationship with the matrix when they precipitated from the carbon supersaturated austenite.

\section{Intermetallic precipitate free zones}

Intermetallic precipitate free zones occur due to solute depletion (because of preferential precipitation at grain boundaries) and/or to a deficiency of suitable nucleation sites (due to vacancy depletion) for precipitation in the vicinity of grain boundaries. Two distinct precipitate free zones, one corresponding to $\gamma^{\prime \prime}$ precipitation and a narrower one corresponding to $\gamma^{\prime}$ precipitation, could be observed near grain boundaries where $\mathrm{NbC}$ carbide precipitation occurred in Alloy 718. Both the $\gamma^{\prime}$ and the $\gamma$ " phases contain niobium, its concentration being higher in $\gamma^{\prime \prime}$ than in $\gamma^{\prime}$ particles. The larger width of the $\gamma^{\prime \prime}$ free zones as compared to the width of the $\gamma^{\prime}$ free zones would imply that solute (niobium) depletion played an important role in the formation of these zones. Vacancy depletion could also have played a part since the volume misfit between $\mathrm{NbC}$ and the austenite was very large and vacancy migration to the growing carbide precipitates would have occurred in order to reduce the local internal stresses. The scarcity of vacancies in the vicinity of carbide precipitates would also inhibit intermetallic phase precipitation in these regions. Kirman and Warrington [20] have indicated that precipitate free zones in niobium bearing nickcl base alloys could arise either due to vacancy or due to solute depletion.

The $\gamma^{\prime \prime}$ denuded zones close to the grain boundaries in Alloy 625 were possibly formed mainly due to solute depletion and not vacancy depletion since the size misfit between the austenite and the $\mathrm{M}_{6} \mathrm{C}$ or the $\mathrm{M}_{23} \mathrm{C}_{6}$ phases was not very large. At agcing temperatures below $850^{\circ} \mathrm{C}$, the carbide phase nucleating at the grain boundaries was predominantly of the $\mathrm{M}_{23} \mathrm{C}_{6}$ type while above this temperature the $\mathrm{M}_{6} \mathrm{C}$ phase nucleated. Raghavan et al. [19] have demonstrated by microanalysis that the growth of $\mathrm{M}_{6} \mathrm{C}$ particles is associated with molybdenum depletion of neighbouring austenite grains while the formation of $\mathrm{M}_{23} \mathrm{C}_{6}$ precipitates causes both chromium and molybdenum depletion in the matrix. This depletion of one or more solute species could lead to an enhancement in the solubility of intermetallic phases in these regions, resulting in the formation of precipitate free zones. Moreover, the ratio of chromium to molybdenum content in Alloy 625 was close to the chromium to molybdenum ratio separating the phase fields for the formation of $\mathrm{M}_{6} \mathrm{C}$ and $\mathrm{M}_{23} \mathrm{C}_{6}$ type phases in Ni-Cr-Mo alloys [19]. EDS analysis of a number 

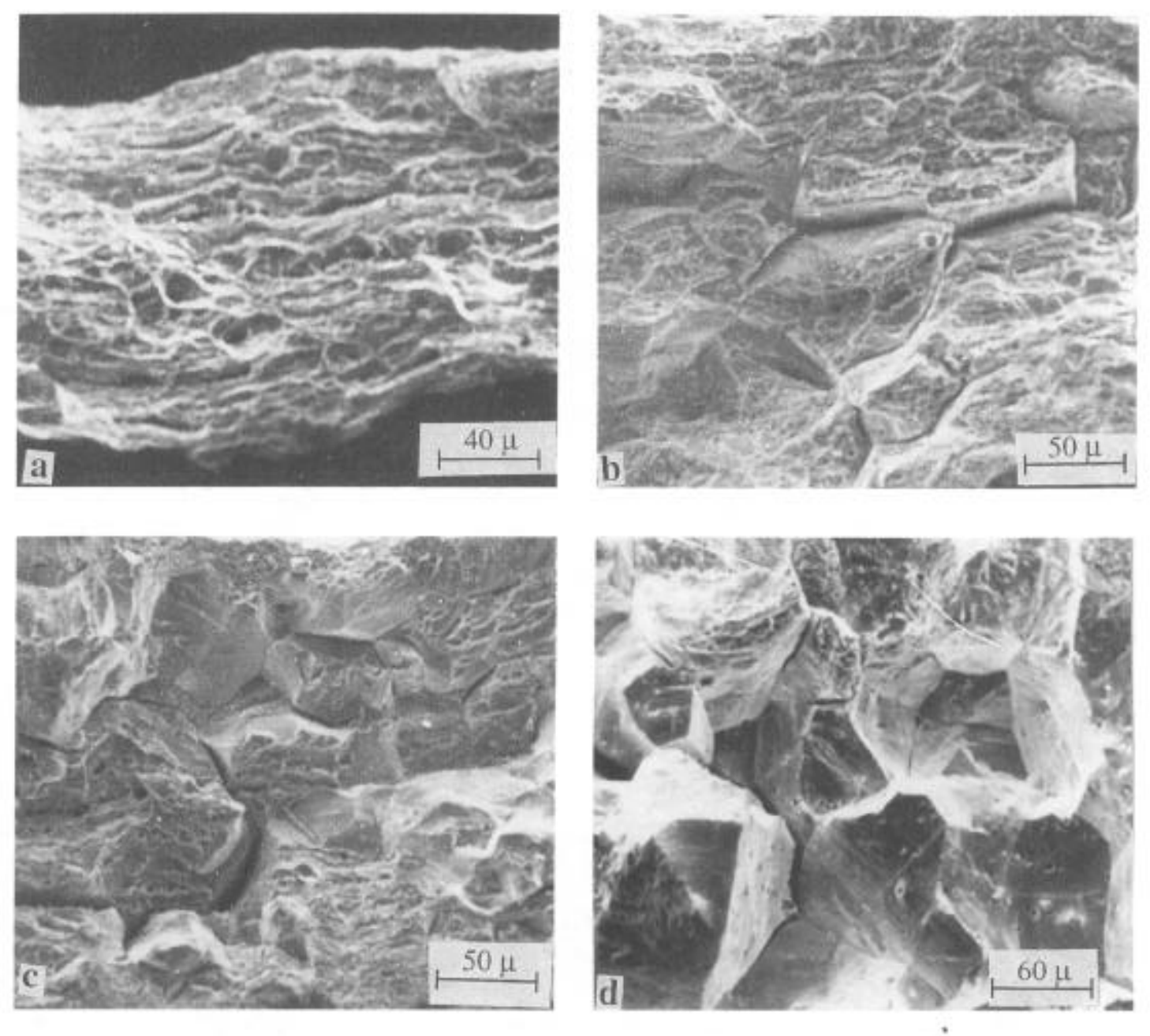

Fig.6. Gradual transition in the fracture mode from transgranular to intergranular in Alloy 625 aged at $650^{\circ} \mathrm{C}$ for (a) $6 \mathrm{~h}$; (b) $24 \mathrm{~h}$; (c ) $96 \mathrm{~h}$; and (d) $200 \mathrm{~h}$. for $100 \mathrm{~h}$; and (d) $900^{\circ} \mathrm{C}$ for $114 \mathrm{~h}$.
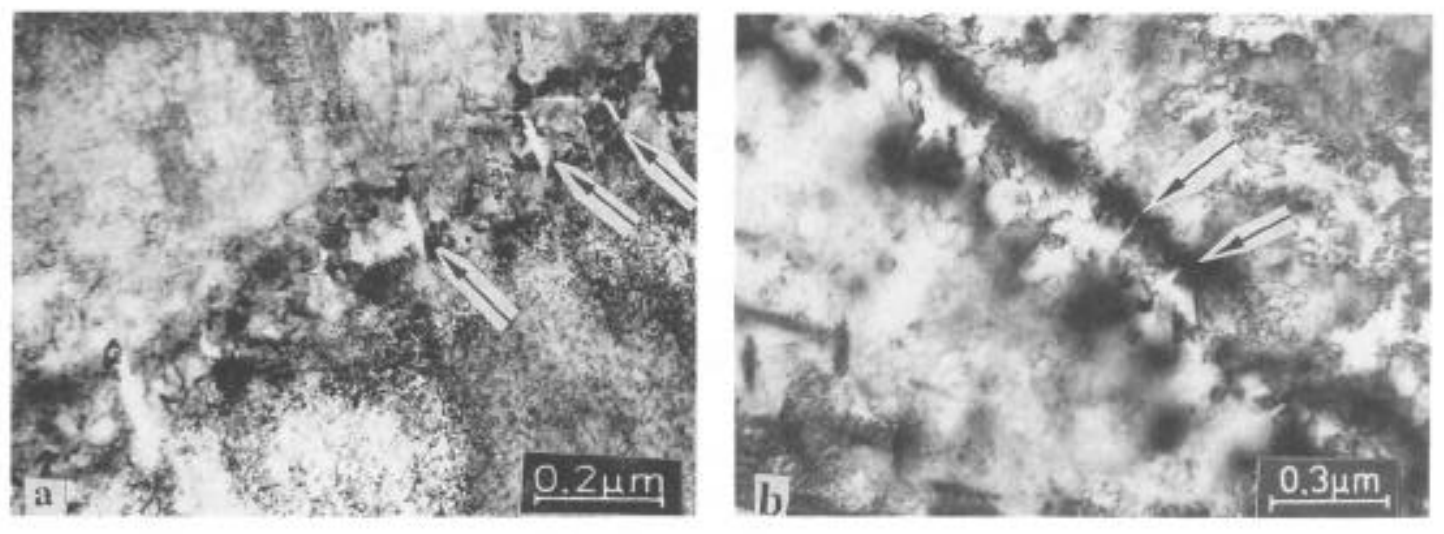

Fig.7. Micrographs illustrating microcracks (indicated by arrows) developed at carbide-matrix interfaces when deformation bands impinge on grain boundary carbides; (a) Alloy 718; (b) Alloy 625. 
of grain boundary carbide particles (to be published elsewhere) in Alloy 625 indicated that the concentrations of chromium and molybdenum varied from grain boundary to grain boundary. The precipitation of either of the carbide phases would cause the neighbouring regions to be denuded of one or more of the solute species. It was not clear why some boundaries with carbide precipitates had no precipitate free zones surrounding them. More experimental work is required to clarify this point.

\section{Effect of grain boundary carbides on alloy fracture mode}

The observed correlation between the formation of closely spaced grain boundary carbide precipitates and the transition in the fracture mode of the alloys from transgranular to intergranular suggested that near continuous carbide layers at grain boundaries provided an easy path to fracture. It appeared that during plastic deformation, when deformation bands impinged on such carbide particle containing grain boundaries, microcracks sometimes developed at the interfaces between the particles and the austenite (Fig.7). Similar observations have been made by Shiozawa and Weertman [21] in the context of grain boundary microcracking in wrought Astroloy, a nickel base superalloy. They have found that straining Astroloy at room temperature results in grain boundary damage in the form of microcracking at the interface between carbide and matrix, close to the ends of the carbide. These microcracks are associated with intense, localised slip and the frequency of their occurrence is roughly independent of the orientation of the grain boundary with respect to the axis of straining. These researchers have suggested that the carbide particles behave as nondeformable inclusions when the neighbouring matrix undergoes plastic deformation and have shown that in such a situation the interfacial stress peaks near the ends of the inclusions. These large stresses can lead to localised relaxation by slip, piling up of dislocations at the inclusions and interfacial tensile stresses that are large enough to cause decohesion at the ends of the inclusion. Moreover, differences in the elastic constants of the matrix and of the inclusion lead to a concentration of shear stress near the ends of the inclusion and this may result in microcracking. When the carbide particles are very closely spaced, forming a near continuous film, the distances separating neighbouring microcracks would be very small and they would easily join up to facilitate intergranular fracture.

\section{Conclusions}

On the basis of the results reported in this paper, the following conclusions could be drawn:

1) 'The primary carbide phases occurring in both the alloys are predominantly of the MC type. 2) Carbide phases that precipitate during ageing nucleate almost exclusively at grain boundaries and on incoherent segments of twin boundaries. The growth of these carbide particles is accompanied by a concomitant formation of intermetallic precipitate free zones in their immediate neighbourhood.

3) The grain boundary carbide precipitates in Alloy 718 are predominantly of a niobium rich $\mathrm{MC}$ phase while those in Alloy 625 are of the $M_{23} C_{6}$ and to some extent of the $M_{6} C$ phases.

4) Carbide precipitates at grain boundaries strongly influence the fracture mode of the alloys by promoting intergranular failure.

\section{Acknowledgments}

The authors are thankful to Dr. C.K. Gupta, Director, Materials Group, for constant encouragement and support. 


\section{References}

1. D.R. Muzyka, The Superalloys, Ed. C.T. Sims and N.C. Hagel, John Wiley, New York, (1972), 113-143.

2. F. Garzarotli, A. Gerscha and K.P. Francke, "Untersuchungen über das Ausscheidungsverhalten und die mechanischen Eigenschaften der Legierung Inconel 625", $\underline{Z}$. Metallkunde, 60 (1969), 643-652.

3. D.F. Paulonis, J.M. Oblak and D.S. Duvall, "Precipitation in Nickel Base Alloy 718", Trans. ASM, 62 (1969), 611-622.

4. M. Sundararaman, P. Mukhopadhyay and S. Banerjee, "Precipitation of the $\delta-\mathrm{Ni}_{3} \mathrm{Nb}$ Phase in Two Nickel Base Superalloys", Metall. Trans. 19A (1988), 453-465.

5. V. Ramaswamy, P.R. Swann and D.R.F. West, "Observations on Intermetallic Compound and Carbide Precipitation in Two Commercial Nickel Base Superalloys", J. Less. Common Metals, 27 (1972), 17-26.

6. H. Bohm, K. Ehrlich and K.H. Kramer, "Das Ausscheidungsverhalten der Nickellegierung Inconel 625", Metall, 24 (1970), 139-144.

7. W.J. Boesch and H.B. Canada, "Precipitation Reactions and Stability of $\mathrm{Ni}_{3} \mathrm{Nb}$ in Inconel 718",J. Metals, 21 (1969) 24-33.

8. S. Floreen, G.E. Fuchs and W.J. Yang, "The Metallurgy of Alloy 625", Superalloys 718. 625. 706 and Various Derivatives, TMS, Pittsburgh, PA, USA (1994), 13-38.

9. C. Vernot-Loier and F. Cortial, "Superalloy 718/625", TMS, Warrendale, PA, USA (1991), 409.

10. M. Sundararaman, P. Mukhopadhyay and S. Banerjee, "Deformation Behaviour of $\gamma$ " Strengthened Inconel 718", Acta Metall., 36 (1988), 847-864.

11. M. Sundararaman and P. Mukhopadhyay, "Carbide Precipitation in Inconel 718", High Temperature Materials and Process, 11 (1993), 351-368.

12. D.V. Edmonds and R.W.K. Honeycombe, "Precipitation Processes in Solids", Ed. K.C. Russell and H.I. Aaronson, The Metallurgical Society of AIME, Warrendale, USA, (1978), 121. 13. H.F. Merrick, "Precipitation Processes in Solids", Ed. K.C. Russell and H.I. Aaronson, The Metallurgical Soceity of AIME, Warrendale, USA, (1978), 161.

14. R.F. Dekker and C.T. Sims, The Superalloys, Ed. C.T. Sims and W.C. Hagel, John Wiley, New York, NY, USA, (1972), 33.

15. G.W. Lorimer, "Precipitate Nucleation", Mater. Sci. Forum, 3 (1985), 199-210.

16. P.N.T. Unwin, G. W. Lorimer and R.B. Nicholson, " The Origin of Grain Boundary Precipitate Free Zone", Acta Metall., 17 (1969),1379-1393.

17. P.H. Pumphrey, "The Role of Special High Angle Grain Boundaries in Precipitate Nucleation", Scripta Metall., 7 (1973), 1043-1046.

18. E.P. Butler and P.R. Swann, "In Situ Observations of the Nucleation and Initial Growth of Grain Boundary Precipitate in an Al-Zn-Mg Alloy", Acta Metall., 24 (1976), 343 -352.

19. M. Raghavan, R.P. Mueller, C.F. Klein and G.A. Vaughn, "Carbides in Ni-Cr-Mo System", Scripta Metall., 17 (1983), 1189-1194.

20. I. Kirman and D.H. Warrington, "The Precipitation of $\mathrm{Ni}_{3} \mathrm{Nb}$ Phases in a $\mathrm{Ni}-\mathrm{Fe}-\mathrm{Cr}-\mathrm{Nb}$ Alloy", Metall. Trans., 1 (1970), 2667-2675.

21. K. Shiozawa and J.R. Weertman, "Studies of Nucleation Mechanisms and the Role of Residual Stresses in the Grain Boundary Cavitation of a Superalloy", Acta Metall., 31 (1983), 993-1004. 